Review

\title{
Current status of endovascular treatment for dural arteriovenous fistula of the transverse-sigmoid sinus: A literature review
}

\author{
Kan $\mathrm{Xu}^{1^{*}}$, Xue Yang ${ }^{*}$, Chao $\mathrm{Li}^{2}$, Jinlu $\mathrm{Yu}^{1 凶}$ \\ 1. Department of Neurosurgery, The First Hospital of Jilin University, Changchun, 130021, China \\ 2. Department of Neurology, The First Hospital of Jilin University, Changchun, 130021, China \\ *These authors contributed equally to this work. \\ $\triangle$ Corresponding author: Jinlu Yu Department of Neurosurgery, The First Hospital of Jilin University, 71 Xinmin Avenue, Changchun 130021, China. E-mail: \\ jlyu@jlu.edu.cn \\ (c) Ivyspring International Publisher. This is an open access article distributed under the terms of the Creative Commons Attribution (CC BY-NC) license \\ (https://creativecommons.org/licenses/by-nc/4.0/). See http://ivyspring.com/terms for full terms and conditions.
}

Received: 2018.06.05; Accepted: 2018.09.14; Published: 2018.10.20

\begin{abstract}
Most intracranial dural arteriovenous fistulae (DAVFs) involve the transverse-sigmoid sinus (TSS), and various types of endovascular treatment (EVT) have been involved in managing TSS DAVFs. A current, comprehensive review of the EVT of TSS DAVFs is lacking. This study used the PubMed database to perform a literature review on TSS DAVFs to increase the current understanding of this condition. For high-grade TSS DAVFs such as Borden type 3, the goal of EVT is curative treatment. However, for low-grade TSS DAVFs such as Borden type 1 and some Borden type 2 TSS DAVFs, symptom relief or elimination of cortical reflux may be sufficient. Currently, EVT has become the first-line treatment for TSS DAVFs, including transarterial embolization (TAE), transvenous embolization (TVE) or both. TAE alone and TSS balloon-assisted TAE are also commonly used. However, TVE for TSS DAVFs is recognized as the most effective treatment, including coil direct packing TSS, Onyx ${ }^{\circledR}$ (ethylene vinyl alcohol copolymer) TVE, and balloon-assisted Ony $x^{\circledR}$ TVE, which are commonly applied. In addition, TSS reconstructive treatment can be an effective procedure to treat TSS DAVFs. EVT is accompanied with complications, including technique- and treatment-related complications. Although complications may occur, TSS DAVFs have an acceptable prognosis after EVT.
\end{abstract}

Key words: endovascular treatment, dural arteriovenous fistula, transverse-sigmoid sinus, review

\section{Introduction}

A dural arteriovenous fistula (DAVF) is an arteriovenous shunt located in the dural wall of the venous sinus or expanded layer of the dura mater [1-3]. Most DAVFs involve the transverse-sigmoid sinus (TSS) [4-6]. To prevent hemorrhage of high-grade TSS DAVFs, such as Borden type 3, or for symptom relief of low-grade TSS DAVFs, such as Borden type 1 and some Borden type 2 TSS DAVFs, endovascular treatment (EVT) is needed [7-9].

Currently, therapeutic strategies for DAVFs primarily include EVT, microsurgery, and stereotactic radiosurgery $[6,10,11]$. Microsurgery is not minimally invasive [12]. Although stereotactic radiosurgery achieves DAVF cure rates of between $58 \%$ and $73 \%$, the latent period ranges from 1 to 3 years, and stereotactic radiosurgery is not usually preferred $[6,13,14]$. Therefore, EVT is more suitable for immediately minimizing the risk of hemorrhage [15].

During the past 2 decades, EVT has become the first-line treatment for TSS DAVFs. EVT includes transarterial embolization (TAE), transvenous embolization (TVE) or both [16-19]. Notably, the invention of large-lumen, highly compliant, inflatable occlusion balloons and the liquid embolic agent Ony $x^{\circledR}($ ev3, Irvine, CA) initiated a new era in EVT for 
the DAVFs [13, 20-23].

Until now, a comprehensive review of EVT for TSS DAVFs has been lacking. Therefore, the current paper reviewed the available literature on the subject. "Transverse-sigmoid sinus" and "dural arteriovenous fistula" were used as search terms in the PubMed database to identify English-language publications.

\section{Critical vessels in the TSS region}

\section{Main meningeal vessel}

Four main meningeal arteries exist in the TSS region: the middle meningeal artery (MMA), ascending pharyngeal artery (APhA), posterior meningeal artery (PMA) and occipital artery (OA) [24, 25]. The posterior division (PD) of the MMA supplies the dura around the torcula, transverse sinus (TS) and sigmoid sinus (SS) [25]. The mastoid transosseous branch (MB) of the OA supplies the dura of the lateral and paramedial cerebellar fossa, including the TS and superior part of the SS [26]. The jugular and hypoglossal branches of the APhA supply the dura of the lower segment of the SS [27]. The PMA arises from the vertebral artery and supplies the dura forming the walls of TS and torcula [24]. The main meningeal vessels are shown in Figure 1.

\section{TS and SS}

The TS originates at the torcular herophili and courses laterally to become the SS at the site immediately behind the petrous ridges [28]. The SS hooks downward along the posterior surface of the mastoid and turns forward on the occipital bone to pass through the sigmoid part of the jugular foramen and opens into the internal jugular vein [29]. The TS receives a number of important supratentorial veins from the temporal and occipital lobes, notably the Labbé vein, and the TS receives drainage from the infratentorial veins, the superior petrosal sinus and diploic veins [30-32]. In addition, the SS connects with the pericranial veins via the mastoid and condylar emissary veins [32-34].

\section{Angioarchitecture and grade}

A thorough understanding of the architecture and the grade/classification of DAVFs is essential for the successful treatment of TSS DAVFs $[13,35]$.

\section{Feeding artery}

The MMA, PMA, and meningeal branches of the APhA and OA are the main feeding arteries to TSS DAVFs [36]. In addition, other meningeal branches, such as the internal carotid artery (ICA) and external carotid artery (ECA), can supply the TSS dura in pathological conditions related to TSS DAVFs, such as transosseous branches of the posterior auricular artery and the superficial temporal artery (STA), the tentorial branches of the meningohypophyseal trunk (MHT), the artery of the falx cerebelli, the posterior inferior cerebellar artery (PICA) and the anterior inferior cerebellar artery (AICA) [1, 17, 21, 36-40]. These small dural branches may not be visible on angiography, but when supplying TSS DAVFs, these small branches may become hypertrophic or enlarged [1].

\section{Fistula point}

The fistula point of a TSS DAVF may be on the TSS while draining into the TSS; the fistula point may be single and limited, but often, the fistula point is multiple and extensive. Thus, clear identification of the diseased segment of the TSS to provide complete embolization may be difficult [41]. The fistula points of TSS DAVFs may be located in the vicinity of the TSS without draining into the TSS [4, 42, 43].

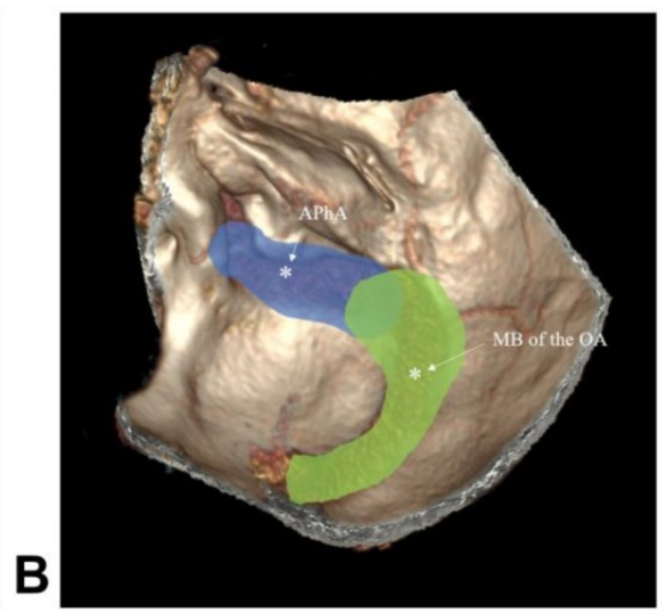

Figure 1. Main meningeal vessel in TSS. A: The red region shows the PD of the MMA; the yellow region shows the PMA; $B$ : the green region shows the MB of the OA; the blue region shows the APhA. Abbreviations TSS: transverse-sigmoid sinus; PD of the MMA: posterior division of the middle meningeal artery; APhA: ascending pharyngeal artery; PMA: posterior meningeal artery; MB of the OA: transosseous branch of the occipital artery. 


\section{Venous drainage}

TSS DAVFs can reverse the blood flow of all neighboring superficial and deep venous structures, including the TSS, superior sagittal sinus (SSS), superior petrosal sinus, basal vein of Rosenthal, the vein of Labbé, and cortical and deep medullary veins, which causes brain venous hypertension [41, 44, 45]. Even the venous reflux can proceed to the brainstem and medulla veins $[46,47]$. Therefore, for TSS DAVFs, supratentorial, infratentorial, brainstem and spinal drainage must be evaluated [43, 47]. Under idiopathic intracranial hypertension, the cortical and intramedullary vessels can become tortuous and ectatic $[32,44]$. Additionally, because the DAVFs are often associated with sinus thrombosis, the TSS can become partially thrombosed or completely occluded [48-50].

TSS stenosis or occlusion indicates sinus dysfunction. For instance, in the Kirsch et al. 2009 study with 150 TSS DAVFs, more than half of the affected sinuses were partially or completely thrombosed [4]. Theoretically, stenotic and thrombosed TSSs impede the venous outflow, and the DAVF itself increases overall blood volume in the affected TSS. The combination of these 2 hemodynamic disorders adversely affects venous flow and subsequently increases intracranial pressure $[2,51]$. The sinovenous outflow restriction may represent a stronger risk factor associated with hemorrhage [44].

\section{Shunted pouch}

The shunted pouch (SP) is defined as a tubular or elliptic vascular structure that is separated from the main sinus lumen into which multiple feeding arteries converge and continue to the sinus. The SP findings include the following: (i) convergence of the feeding arteries, (ii) separation from the main lumen of the dural sinus, (iii) caliber change at the fistulous point, and (iv) contrast gradient and continuity to the main lumen of the dural sinus $[43,52,53]$.

The SP is common in TSS DAVFs. For instance, Kiyosue et al. in 2013 studied 25 consecutive cases of TSS DAVFs; multiplanar reformatted images and selective angiography were reviewed with a particular focus on the SPs. These authors found that all 25 cases showed SPs, with numbers ranging from 1 to 4 pouches. SPs are important in TSS DAVF EVT; if the SP can be embolized, the DAVF can be cured [54].

\section{Arterial steal phenomenon}

In TSS DAVFs, if the DAVF is high-flow or extensive, the arterial steal phenomenon can occur [55]. For instance, in 2017, Kerolus et al. reported an illustrative case of TSS DAVF due to high flow PMA feeding. Digital subtraction angiography (DSA) of the left vertebral artery revealed a steal phenomenon presenting with a cutoff sign in which the fistula was stealing blood flow from the VA, thereby preventing sufficient blood flow to the distal segment of the VA [41].

\section{Grade and classification}

\section{(i) Grade}

In TSS DAVFs, retrograde venous drainage is commonly directed towards the deep venous system via the SS and towards the cerebral convexity via the SSS [2]. It is now generally accepted that the venous drainage pattern of DAVFs is the most predictive factor [8]. The grading systems of Borden et al. [56] and Cognard et al. [57] are the most widely used to evaluate the venous drainage and predict hemorrhage based on angiographic features with an emphasis on the presence of cortical venous reflux [5].

Many TSS DAVFs are high-grade. For instance, in a study by Cho et al. in 2013 with 38 patients, $71.1 \%$ had Borden type 2 or 3 lesions (high-grade) [10]. In the study by Kirsch et al. in 2009 with 150 TSS DAVFs, according to the Cognard classification, the venous drainage was type I in $31 \%$, type IIa in $29 \%$, type IIb in $20 \%$, type III in $17 \%$, and type IV in $3 \%$ of cases. Therefore, type IIb-IV (high-grade) accounted for $40 \%$ of cases [4].

\section{(ii) Classification}

The classification system of TSS DAVFs devised by Lalwani et al. in 1993 is useful for determining the best treatment strategy. Depending on venous drainage patterns, the TSS DAVFs can be divided into 4 grades: Grade 1, antegrade sinus drainage without TSS stenosis or cortical venous reflux; Grade 2, antegrade and retrograde sinus drainage with proximal TSS stenosis, with or without cortical venous reflux; Grade 3, retrograde sinus drainage with proximal TSS occlusion and cortical venous reflux; and Grade 4, cortical venous reflux only $[8,49]$.

\section{Outline of endovascular treatment}

For high-grade TSS DAVFs, the goals of EVT are complete obliteration of the fistula, correction of the venous shunting, and reversal or occlusion of the cortical venous reflux [51]. The therapeutic success standard is as follows: in angiography, the DAVF has a $>95 \%$ reduction, and the cortical venous drainage is absent [2]. However, for low-grade TSS DAVFs, symptom relief or elimination of cortical reflux are sufficient [7-9].

The treatments for TSS DAVFs included TAE, TVE and a combination of both $[58,59]$. Currently, TAE is extensively used, especially after the 
introduction of the latest embolizing material, Onyx ${ }^{\circledR}$, which can be controllably delivered into the fistula $[22,60]$. However, for TSS DAVFs, TVE is a more effective treatment; moreover, the combination of TAE and TVE is also useful [43]. For EVT of TSS DAVFs, treatment approaches can be performed by femoral artery and vein, jugular vein or a direct burr hole [61-64].

During the EVT, the SPs play an important role. After the microcatheter accesses the SPs, TSS DAVFs can be successfully treated with the selective embolization of the SPs by TAE or TVE. Even in cases treated by selective occlusion of the SP, the shunted blood flow can be significantly reduced $[43,53,65]$.

The treatment of TSS DAVFs should be based on the angioarchitecture and cortical venous reflux. Therefore, it is feasible to divide the TSS DAVFs into different types according to the appropriate treatment [43]. The classification system of TSS DAVFs devised by Lalwani et al. in 1993, which consists of four grades, was the most reasonable [49].

Grade 1 TSS DAVFs had antegrade sinus drainage without TSS stenosis or cortical venous reflux; in this grade, TAE or combined radiation therapy is sufficient [49]. Grade 2 TSS DAVFs have antegrade and retrograde sinus drainage with proximal TSS stenosis, with or without cortical venous reflux; in this grade, TAE and TVE can be applied; however, occlusion of the normal cortical venous drainage system should be avoided [13, 49, 66].

Grade 3 TSS DAVFs have retrograde sinus drainage with proximal TSS occlusion and cortical venous reflux. Grade 3 DAVFs can be treated with TVE, and the affected sinus and retrograde cortical drainage outlet should be tightly packed with coils $[13,49]$. Grade 4 TSS DAVFs have cortical venous reflux only and are the most difficult type of dural AVF to treat. In this grade, TAE and TVE can be applied for complete obliteration of the fistula $[8,49]$.

\section{Transarterial embolization}

The goal of TAE in TSS DAVF is the obliteration of all feeding arteries and proximal draining veins together with the preservation of the patency of the affected TSS [13, 66]. Currently, TAE with preservation of the TSS has become the preferred approach due to the development of Ony $x^{\circledR}$ [20]. TSS balloon-assisted TAE is also commonly applied [67].

\section{TAE alone}

During TAE, the goal is for Ony $x^{\circledR}$ to penetrate the fistula points and proximal venous outflow to assure complete embolization; thus, it is very critical that the microcatheter be placed in the appropriate tip position $[17,68]$. Theoretically, TAE alone via the most promising feeding artery may obliterate the DAVF filling in one injection. In particular, the usage of Ony ${ }^{\circledR}$ allows better control and a more accurate injection, which has increased interest in the TAE approach and has improved obliteration rates $[13,66]$.

However, if the TSS DAVF has multiple fistula points or is extensive and drains into the TSS, TAE alone may not be sufficient to cure the TSS DAVF [41]. The main reason for this phenomenon is that the feeding arteries of TSS DAVFs have extensive collateral networks, thus complicating complete closure via an arterial route [13, 66]. The second reason is that the venous drainage into the TSS prevents unlimited Onyx ${ }^{\circledR}$ casting in the DVAF to avoid TSS occlusion $[13,66]$. Therefore, the immediate postprocedural occlusion rate after TAE is only $30 \%$ [4]. In addition, even if the TSS DAVF is successfully embolized by TAE, due to the existence of DAVF inducing factors, the TSS DAVF may continue to draw feeders from other sources and may later recur and result in hemorrhage [17, 69-73].

However, if the TSS has focal occlusion or an isolated segment presenting with venous sinus irregularity in DSA suggestive of previous sinus thrombosis and partial recanalization [38] or if the fistula point of the TSS DAVF is located in the vicinity of the TSS without draining into the TSS, TAE alone without consideration of the TSS is very effective [4, 42].

The MMA is straight and fixed between the dura and is therefore commonly used as a means to access TSS DAVFs because the MMA allows unlimited Onyx ${ }^{\circledR}$ casting [25]. Even if the branches of the MMA are not the main feeders, the MMA allows a long reflux and thus represents the safest route to access the TSS DAVF [74]. At this time, the dual-lumen balloon technique may be very useful in performing TAE [17, 21, 75, 76]; this technique is also known as the pressure cooker technique [77, 78]. However, caution should be exercised during TAE via the MMA because embolization of the petrosal branch of the MMA carries a risk of facial nerve palsy [79].

With the exception of MMA, other transarterial approaches, such as the OA, APhA and STA, can also be used under the assistance of a dual-lumen balloon or a Marathon microcatheter (ev3, Neurovascular) associated with a Hyperglide or HyperForm balloon (ev3 Neurovascular) [21, 67, 80, 81]. For instance, in 2016, Clarençon et al. treated two patients with TSS DAVFs through the OA and/or the STA with Ony ${ }^{\circledR}$ using a Scepter double-lumen balloon (Microvention, Tustin, CA, USA). The balloon allows the Onyx ${ }^{\circledR}$ to penetrate the transosseous branches by creating counter-pressure with the inflated balloon [21]. 


\section{TSS balloon-assisted TAE}

When the TSS DAVF drains into the TSS and the fistula points are multiple and extensive, it is difficult to complete embolization by TAE alone because the drainage into the TSS prevents unlimited Onyx ${ }^{\circledR}$ casting [20, 41, 82]. At this time, a TSS balloon-assisted TAE technique with Onyx ${ }^{\circledR}$ embolization may be a good choice; the remodeling balloon in the TSS allows Ony $x^{\circledR}$ to better infiltrate along the DAVF site but not fill the entire TSS [66, 83, 84]. In addition, an appropriate inflating pressure for the balloon enables the blood flow in the TSS to decrease and favor optimal Ony $x^{\circledR}$ penetration $[66,83]$.

TSS balloon-assisted TAE can be performed safely and effectively. For instance, Jittapiromsak et al. in 2013 treated a series of DAVFs with a low-pressure compliant balloon in TSS protection [66]. In this procedure, the transarterial microcatheter is navigated to the target position in a main feeder close to the fistula point where the Onyx ${ }^{\circledR}$ injection is intended to start. This should be performed in the first stage; in the second stage, a venous remodeling balloon should be placed within the TSS-affected segment $[17,21]$.

In TSS balloon-assisted TAE, the venous access by direct jugular puncture access is superior to the transfemoral route because it provides improved support for balloon navigation [66]. In the technique, it is important to identify collateral venous drainage, and any balloon position with an appearance of normal venous outflow stagnation should be avoided. Moreover, temporary deflations of the balloon (normally within 3-5 $\mathrm{min}$ ) are usually performed during the pauses of Onyx ${ }^{\circledR}$ injection to allow temporary drainage of the normal venous path, especially in the dominant sinus or in cases involving normal cortical arteries [13, 21, 66, 82, 85].

\section{Transvenous embolization}

TVE for TSS DAVFs is currently recognized as one of the most effective treatments $[1,2]$. Coil direct packing of the TSS, Onyx ${ }^{\circledR}$ TVE, and balloon-assisted Ony $x^{\circledR}$ TVE are also commonly applied $[13,43,59,86]$.

\section{Coiling TVE}

Coiling TVE is used for curative purposes. Coil packing occlusion of the TSS via a transvenous approach is usually well tolerated and highly effective $[32,87]$. Especially in cases of TSS DAVFs with TSS stenosis or occlusion, it is appropriate to perform coil packing in the affected TSS due to its dysfunctional state [48]. Because the occluded sinuses are permeated by small channels, it is often difficult to reach into the isolated sinus, and a stiff 0.035 -inch guidewire may be useful to pass the occluded TSS. It may sometimes be feasible to access the lesion from the contralateral TSS [88-90]. Even the transcranial exposure of the TSS for surgically assisted direct TVE is more practical [62].

Coiling TVE can be accomplished with bare and fibered coils [4]. Onyx ${ }^{\circledR}$ can sometimes be combined with this method to occlude the TSS [43, 91]. However, when the contralateral venous sinuses are hypoplastic, the TSS balloon occlusion test is required. If there is no contrast stagnation in the cortical veins, SSS and contralateral TSS, coiling TVE can be performed [13, 43, 48].

In coiling TVE when treating DAVF, it became apparent that dense coil packing of the entire sinus segment involved in the DAVF would result in the complete obliteration of the fistula [48]. If coil occlusion of the TSS cannot be performed completely, combination with TAE may be a very effective treatment method [92]. In addition, a delayed thrombosis of a residual DAVF can be observed after coil occlusion of TSS; therefore, it is worth waiting a few weeks after transvenous packing of the TSS [4, 13]. For the coiling packing TSS technique for DAVFs, treatment with low molecular weight heparin for three days followed by aspirin is necessary to prevent cortical vein thrombosis around the DAVF due to sacrificing the TSS [88].

\section{Onyx® TVE}

Currently, Onyx ${ }^{\circledR}$ TVE is usually performed in cases of carotid cavernous fistulas [93]. Occasionally, the Ony ${ }^{\circledR}$ TVE technique can also be used in brain arteriovenous malformations (AVM) [94]. However, Ony $x^{\circledR}$ TVE for AVMs is dangerous due to the fragile nature of the veins that likely predispose patients to hemorrhage [77, 95]. However, the effect of catheter adhesion is less of a concern in cases of DAVFs involving the TSS; in this setting, the dural leaves are substantially thicker than the cerebral veins, thus making Onyx ${ }^{\circledR}$ TVE feasible [96].

Theoretically, the TSS DAVFs can be treated by Onyx ${ }^{\circledR}$ TVE, which is attributed to the unique properties of Onyx ${ }^{\circledR}$ that enhance distal propagation into multiple feeding arteries [23]. For instance, Albuquerque et al. in 2014 successfully treated two patients with high risk TSS DAVFs by Ony $x^{\circledR}$ TVE; a single Onyx ${ }^{\circledR}$ infusion from the position of the drainage vein filled multiple arterial feeders and cured TSS DAVFs by retrograde embolization [97]. In the technique of TSS DAVF by Ony ${ }^{\circledR}$ treatment, only cases in which an SP or a large draining vein can allow a microcatheter to navigate through the draining venous pouch and into the ostium of an arterial feeder should be selected [43, 53, 88, 97].

Presumably, in TSS DAVFs that drain directly into the TSS and do not have an SP, stable 
transvenous to arterial catheterization would be more difficult to achieve and would raise the probability of refluxing Onyx ${ }^{\circledR}$ into the normal sinus, which can require balloon-assisted Ony $x^{\circledR}$ TVE $[53,98]$.

\section{Balloon-assisted Onyx ${ }^{\circledR}$ TVE}

Kerolus et al. in 2017 introduced a new Onyx ${ }^{\circledR}$ tunnel technique to embolize DAVFs with TSS preservation. In this approach, after a longer and larger balloon occupies the central lumen of the TSS, a microcatheter is placed between the vessel wall of the TSS and the balloon. After the balloon is fully inflated, Ony ${ }^{\circledR}$ is injected to create a 360-degree tunnel against the TSS wall to encompass the entirety of the complex DAVF [41]

During the Onyx ${ }^{\circledR}$ tunnel technique, it is important to protect the vein of Labbé using an additional balloon, but protecting the vein may not always be necessary because it may not be needed for normal venous drainage [41, 85]. However, the preservation of functionally dependent veins is essential to avoid venous infarction or hemorrhage. Thus, the TSS balloon occlusion test is important, and if contrast stagnation of the cortical veins, contralateral TSS and SSS are observed, the TSS must be preserved [88].

\section{TSS reconstruction}

Coil TVE to sacrifice the TSS is now recognized as one of the most effective treatments for TSS DAVFs. However, in the case of hypoplasia of the contralateral TSS, complete occlusion of the ipsilateral TSS may cause fatal consequences. These results come at the cost of a higher complication rate 33\% [13]. In TSS DAVFs, mild-to-moderate TSS stenosis (a diameter less than $50 \%$ of the diameter of the normal TSS at the stenotic segment) is present in nearly one-third of cases [15]. In this situation, reconstructive treatment using a stent graft with or without TAE of the TSS DAVF can be an effective procedure to occlude the DAVF and preserve cerebral venous sinus drainage [51].

\section{TSS reconstruction without TAE}

TSS reconstruction is feasible to cure TSS DAVF with sinus stenosis or occlusion because the stent in TSS pushes back the organized fibrous tissue toward the sinus wall, closing the fistulae by compression of the dural SP where the arteriovenous connections lie $[53$, 99, 100]. Moreover, the reconstruction of obstruent TSS can transfer more blood from retrograde cortical and intramedullary venous drainage to the TSS $[50,88]$. For instance, Murphy et al. in 2000 reported a DAVF with a thrombosed TSS. The DAVF flow was reduced after balloon angioplasty, and after the six overlapping stents were subsequently placed from the TS to the proximal internal jugular vein to reconstruct the sinus, postoperative DSA showed the recovery of antegrade venous drainage as well as complete eradication the TSS DAVF [36].

However, not all TSS DAVFs can be cured by stent TSS reconstruction alone [100, 101]. For instance, Levrier et al. in a 2009 study investigated 10 patients with TSS DAVFs with or without sinus thrombosis who underwent self-expanding stent placement and balloon angioplasty in a venous sinus to improve normal venous drainage in the DAVF, followed by bare stent placement. Although symptoms improved as venous drainage improved, only $40 \%$ of cases showed complete cure, as determined on follow-up angiography [99]. Therefore, the combination of TSS stent placement and TAE may be required [101, 102].

\section{Combined TSS reconstruction and TAE}

The combination of TSS reconstruction and TAE is sometimes useful for TSS DAVFs after balloon-expandable stent graft deployment. If the blood leaks into the TSS by repeated and high-pressure balloon inflation, the additional TAE using coils or Onyx ${ }^{\circledR}$ appears to be necessary for remnant DAVF [101, 102]. For instance, Choi et al. in 2009 reported reconstructive TSS using a stent graft for a TSS DAVF with hypoplasia of the contralateral venous sinuses. There were no new neurological findings in the patient after balloon-expandable stent graft deployment at the TSS, and the remnant DAVF flow between the stent graft and venous sinus was treated with coil TAE [1].

\section{Complications}

The cumulative complication rate was 9\% in EVT of TSS DAVFs, including technique complications and treatment-related complications, which can present as hemorrhagic or ischemic $[4,21,48]$.

\section{Technique complications}

These complications are defined as any technical problem with the material used or any medical problem that occurs during the intervention, including vessel or sinus perforation, inadvertent embolization of nontarget vessels, microcatheter rupture and failure to complete the treatment $[13,17$, 38]. Technique complications can be disastrous [38].

\section{Intracranial hemorrhage}

Intracranial hemorrhage was the worst complication in EVT of TSS DAVFs and was caused by Ony $x^{\circledR}$ reflux into normal cortical veins. In addition, TSS can compromise normal cerebral 
venous drainage and produce venous hemorrhage $[10,13,103,104]$.

\section{Cranial nerve palsy}

TAE of TSS DAVFs with Onyx ${ }^{\circledR}$ carries the risk of cranial nerve $(\mathrm{CN})$ palsy, because the feeding artery of the TSS DAVF may have dangerous anastomoses with the arterial supply to the CNs, including CNs VII, IX, $\mathrm{X}, \mathrm{XI}$, and XII $[21,45,59,84]$. The blood supply of $\mathrm{CN}$ VII originates from the petrosal artery of the MMA [105]. The blood supplies of CNs IX, X and XI originate from the jugular branches of the $\mathrm{OA}$ and AphA, and the blood supply of CN XII originates from the hypoglossal branches of the OA and AphA [24]. Therefore, TAE via these arteries may compromise the $\mathrm{CN}$ blood supplies and thus result in $\mathrm{CN}$ palsies. Among the $\mathrm{CNs}, \mathrm{CN}$ VII is often involved in palsy $[106,107]$.

\section{Venous hypertension and thrombosis}

Sacrificing the TSS might cause impaired venous drainage that results in massive intracranial venous hypertension [1]. In addition, after EVT, the venous drainage can become slow and lead to stasis, which can cause venous thrombosis [13]. Therefore, treatment with low molecular weight heparin for three days followed by aspirin is necessary [88].

\section{Onyx ${ }^{\circledR}$ venous propagation}

Theoretically, aggressive Onyx TVE can produce symptomatic cardiac and pulmonary embolization, but it is rare $[103,104,108]$. In addition, during EVT, the inadvertent propagation of Onyx ${ }^{\circledR}$ can migrate into the proximal brain vein despite balloon inflation inside the TSS [13].

\section{Inner ear dysfunction}

For TSS DAVFs, occlusion of the distal SS may result in inner ear dysfunction. The causes may include the occlusion of veins of the cochlear aqueduct and vestibular aqueduct or the mechanical compression of the endolymphatic sac due to thrombosis or dense coil packing [109-111].

\section{Prognosis}

After EVT, TSS DAVFs have an acceptable prognosis [13, 17, 59, 106, 112]. For instance, Kirsch et al., in a 2009 study of 150 TSS DAVFs, reported that after EVT, the angiographic cure rate was $54 \%$. At follow-up, $88 \%$ of patients with residual shunting after the treatment showed complete occlusion [4]. In the Kirsch et al. study, EVT included TAE alone, TVE alone and the combination of both; no TSS reconstruction was performed [4].
TSS reconstruction can also result in a good prognosis of TSS DAVFs. For instance, Levrier et al. in a 2006 study investigated 10 TSS DAVF patients who underwent self-expanding stent placement with balloon angioplasty, and all patients were cured or experienced significant clinical improvement without severe or permanent complications [99]. Therefore, various types of EVT can result in satisfactory outcomes.

However, for TSS DAVFs, after EVT, remnant DAVFs and recurrence are possible [106]. For instance, in a 2013 study by Cho et al., five of 38 patients (13.2\%) exhibited recurrence during follow-up [10]. After the recurrence, repeated EVT or assisted radiotherapy was effective [6, 13, 14]. Therefore, follow-up imaging evaluation is important, and currently, the golden standard of follow-up imaging evaluation of TSS DAVFs remains DSA. In addition, MRA is effective and could be used to evaluate the presence or absence of retrograde venous drainage in patients with DAVFs involving the TSS after treatment [113]. Moreover, the combination of MRI and DSA is more useful [114].

\section{Summary}

For high-grade TSS DAVFs such as Borden type 3 , the goal of EVT is curative treatment. However, for low-grade TSS DAVFs such as Borden type 1 and some Borden type 2 TSS DAVFs, symptom relief or elimination of cortical reflux may be sufficient. Currently, EVT has become the first-line treatment for TSS DAVFs, including TAE, TVE or both. TAE alone and TSS balloon-assisted TAE are also commonly used. However, TVE for TSS DAVFs is recognized as the most effective treatment, including coil direct packing TSS, Onyx ${ }^{\circledR}$ TVE, and balloon-assisted Onyx ${ }^{\circledR}$ TVE, which are commonly applied. In addition, TSS reconstruction can be an effective procedure to treat TSS DAVFs. EVT is accompanied by complications, including technique- and treatment-related complications. Although complications may occur, TSS DAVFs have an acceptable prognosis after EVT.

\section{Typical case}

A 48-year-old man who presented with subarachnoid hemorrhage was admitted to our hospital. The DSA showed a TSS DAVF, and the feeding arteries included the petrous branch of the MMA and PMA. The venous drainage presented with cortical venous reflux. The TSS DAVF was embolized by PD of the MMA via a double-lumen balloon, which is known as the pressure cooker technique. After TAE, the TSS DAVF was cured. The typical case is shown in Figure 2. 

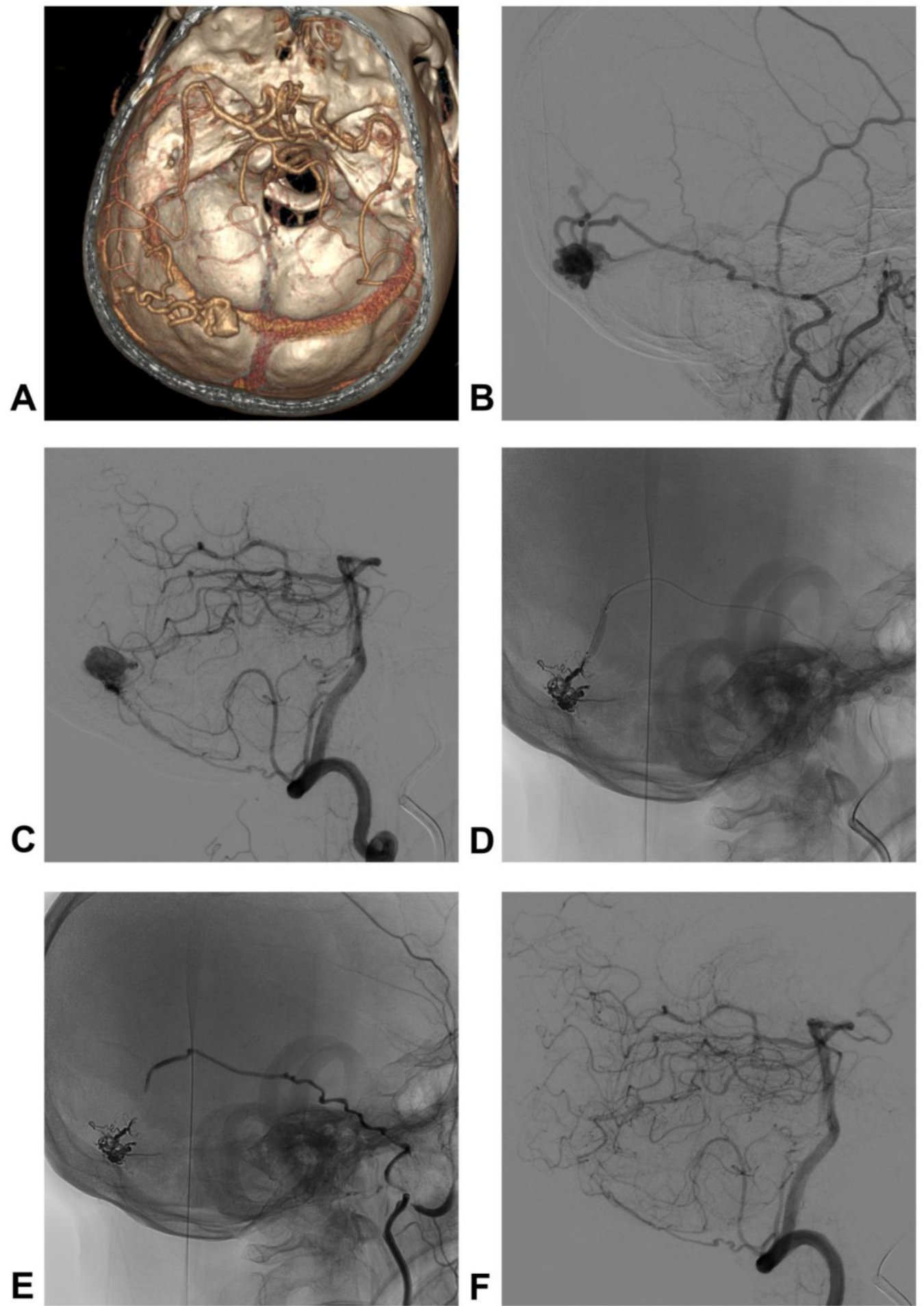

Figure 2. Images of a typical case. A: CTA shows the dilated veins on the left TS, suggestive of DAVF; B: DSA of the left ECA shows the TS DAVF; PD of the MMA was the main feeding artery, and cortical venous reflux was observed; C: DSA of the vertebral artery showed that the PMA was also a feeding artery; D: the TS DAVF was embolized by PD of the MMA via a double-lumen balloon, which is known as the pressure cooker technique; E-F: DSA of ECA and vertebral artery show that the TS DAVF was cured. Abbreviations CTA: computed tomographic angiography; TS: transverse sinus; DAVF: dural arteriovenous fistula; DSA: digital subtraction angiography; ECA: external carotid artery; PD of the MMA: posterior division of middle meningeal artery; PMA: posterior meningeal artery.

\section{Competing Interests}

The authors have declared that no competing interest exists.

\section{References}

1. Choi BJ, Lee TH, Kim CW, Choi CH. Reconstructive treatment using a stent graft for a dural arteriovenous fistula of the transverse sinus in the case of hypoplasia of the contralateral venous sinuses: technical case report. Neurosurgery. 2009; 65: E994-6; discussion E6. 
2. Ghobrial GM, Marchan E, Nair AK, Dumont AS, Tjoumakaris SI, Gonzalez LF, et al. Dural arteriovenous fistulas: a review of the literature and a presentation of a single institution's experience. World Neurosurg. 2013; 80: 94-102.

3. Hamada $\mathrm{Y}$, Goto $\mathrm{K}$, Inoue $\mathrm{T}$, Iwaki $\mathrm{T}$, Matsuno $\mathrm{H}$, Suzuki $\mathrm{S}$, et al Histopathological aspects of dural arteriovenous fistulas in the transverse-sigmoid sinus region in nine patients. Neurosurgery. 1997; 40: 452-6; discussion 6-8.

4. Kirsch M, Liebig T, Kuhne D, Henkes H. Endovascular management of dural arteriovenous fistulas of the transverse and sigmoid sinus in 150 patients. Neuroradiology. 2009; 51: 477-83.

5. Piippo A, Laakso A, Seppa K, Rinne J, Jaaskelainen JE, Hernesniemi J, et al. Early and long-term excess mortality in 227 patients with intracranial dural arteriovenous fistulas. J Neurosurg. 2013; 119: 164-71.

6. Pan DH, Chung WY, Guo WY, Wu HM, Liu KD, Shiau CY, et al. Stereotactic radiosurgery for the treatment of dural arteriovenous fistulas involving the transverse-sigmoid sinus. J Neurosurg. 2002; 96: 823-9.

7. Olutola PS, Eliam M, Molot M, Talalla A. Spontaneous regression of a dural arteriovenous malformation. Neurosurgery. 1983; 12: 687-90.

8. Kiyosue H, Hori Y, Okahara M, Tanoue S, Sagara Y, Matsumoto S, et al. Treatment of intracranial dural arteriovenous fistulas: current strategies based on location and hemodynamics, and alternative techniques of transcatheter embolization. Radiographics. 2004; 24: 1637-53

9. Saito A, Furuno Y, Nishimura S, Kamiyama H, Nishijima M. Spontaneous closure of transverse sinus dural arteriovenous fistula: case report. Neurol Med Chir (Tokyo). 2008; 48: 564-8.

10. Cho WS, Han JH, Kang HS, Kim JE, Kwon OK, Oh CW, et al. Treatment outcomes of intracranial dural arteriovenous fistulas of the transverse and sigmoid sinuses from a single institute in Asia. J Clin Neurosci. 2013; 20: 1007-12.

11. Goto $\mathrm{K}$, Sidipratomo $\mathrm{P}$, Ogata $\mathrm{N}$, Inoue $\mathrm{T}$, Matsuno $\mathrm{H}$. Combining endovascular and neurosurgical treatments of high-risk dural arteriovenous fistulas in the lateral sinus and the confluence of the sinuses. J Neurosurg. 1999; 90: 289-99.

12. Shen SC, Tsuei YS, Chen WH, Shen CC. Hybrid surgery for dural arteriovenous fistula in the neurosurgical hybrid operating suite. BMJ Case Rep. 2014; 2014.

13. Ertl L, Bruckmann H, Kunz M, Crispin A, Fesl G. Endovascular therapy of low- and intermediate-grade intracranial lateral dural arteriovenous fistulas: a detailed analysis of primary success rates, complication rates, and long-term follow-up of different technical approaches. J Neurosurg. 2017; 126: 360-7.

14. Friedman JA, Pollock BE, Nichols DA, Gorman DA, Foote RL, Stafford SL. Results of combined stereotactic radiosurgery and transarterial embolization for dural arteriovenous fistulas of the transverse and sigmoid sinuses. J Neurosurg. 2001; 94: 886-91.

15. Tonetti DA, Gross BA, Jankowitz BT, Atcheson KM, Kano H, Monaco EA, et al. Stereotactic Radiosurgery for Dural Arteriovenous Fistulas without Cortical Venous Reflux. World Neurosurg. 2017; 107: 371-5.

16. Liebig T, Henkes H, Brew S, Miloslavski E, Kirsch M, Kuhne D. Reconstructive treatment of dural arteriovenous fistulas of the transverse and sigmoid sinus: transvenous angioplasty and stent deployment. Neuroradiology. 2005; 47: 543-51.

17. Piechowiak E, Zibold F, Dobrocky T, Mosimann PJ, Bervini D, Raabe A, et al. Endovascular Treatment of Dural Arteriovenous Fistulas of the Transverse and Sigmoid Sinuses Using Transarterial Balloon-Assisted Embolization Combined with Transvenous Balloon Protection of the Venous Sinus. AJNR Am J Neuroradiol. 2017; 38: 1984-9.

18. Kuwayama N. Epidemiologic Survey of Dural Arteriovenous Fistulas in Japan: Clinical Frequency and Present Status of Treatment. Acta Neurochir Suppl. 2016; 123: 185-8.

19. Hiramatsu M, Sugiu K, Hishikawa T, Haruma J, Tokunaga K, Date I, et al. Epidemiology of Dural Arteriovenous Fistula in Japan: Analysis of Japanese Registry of Neuroendovascular Therapy (JR-NET2). Neurol Med Chir (Tokyo). 2014; 54 Suppl 2: 63-71

20. Alturki AY, Enriquez-Marulanda A, Schmalz P, Ogilvy CS, Thomas AJ. Transarterial Onyx Embolization of Bilateral Transverse-Sigmoid Dural Arteriovenous Malformation with Transvenous Balloon Assist-Initial U.S. Experience with Copernic RC Venous Remodeling Balloon. World Neurosurg. 2018; 109: 398-402.

21. Clarencon F, Di Maria F, Gabrieli J, Carpentier A, Pistochi S, Bartolini B, et al. Double-lumen balloon for $\operatorname{Onyx}(\mathrm{R})$ embolization via extracranial arteries in transverse sigmoid dural arteriovenous fistulas: initial experience. Acta Neurochir (Wien). 2016; 158: 1917-23.

22. Shi ZS, Loh Y, Gonzalez N, Tateshima S, Feng L, Jahan R, et al. Flow control techniques for Onyx embolization of intracranial dural arteriovenous fistulae. J Neurointerv Surg. 2013; 5: 311-6.

23. $\mathrm{Hu}$ YC, Newman CB, Dashti SR, Albuquerque FC, McDougall CG. Cranial dural arteriovenous fistula: transarterial Onyx embolization experience and technical nuances. J Neurointerv Surg. 2011; 3: 5-13.

24. Martins C, Yasuda A, Campero A, Ulm AJ, Tanriover N, Rhoton A, Jr. Microsurgical anatomy of the dural arteries. Neurosurgery. 2005; 56: 211-51; discussion -51

25. Yu J, Guo Y, Xu B, Xu K. Clinical importance of the middle meningeal artery: A review of the literature. Int J Med Sci. 2016; 13: 790-9.

26. Alvernia JE, Fraser K, Lanzino G. The occipital artery: a microanatomical study. Neurosurgery. 2006; 58: ONS114-22; discussion ONS-22.
27. Hacein-Bey L, Daniels DL, Ulmer JL, Mark LP, Smith MM, Strottmann JM, et al. The ascending pharyngeal artery: branches, anastomoses, and clinical significance. AJNR Am J Neuroradiol. 2002; 23: 1246-56.

28. Matsushima K, Kohno M, Komune N, Miki K, Matsushima T, Rhoton AL, Jr. Suprajugular extension of the retrosigmoid approach: microsurgical anatomy. J Neurosurg. 2014; 121: 397-407.

29. Matsushima K, Funaki T, Komune N, Kiyosue H, Kawashima M, Rhoton AL, Jr. Microsurgical anatomy of the lateral condylar vein and its clinical significance. Neurosurgery. 2015; 11 Suppl 2: 135-45; discussion 45-6.

30. Rhoton AL, Jr. The cerebrum. Anatomy. Neurosurgery. 2007; 61: 37-118; discussion -9.

31. Katsuta T, Rhoton AL, Jr., Matsushima T. The jugular foramen: microsurgical anatomy and operative approaches. Neurosurgery. 1997; 41: 149-201; discussion -2 .

32. Endo S, Kuwayama N, Takaku A, Nishijima M. Direct packing of the isolated sinus in patients with dural arteriovenous fistulas of the transverse-sigmoid sinus. J Neurosurg. 1998; 88: 449-56.

33. Rhoton AL, Jr. Jugular foramen. Neurosurgery. 2000; 47: S267-85.

34. Rhoton AL, Jr. The posterior fossa veins. Neurosurgery. 2000; 47: S69-92.

35. Obrador S, Soto M, Silvela J. Clinical syndromes of arteriovenous malformations of the transverse-sigmoid sinus. J Neurol Neurosurg Psychiatry. 1975; 38: 436-51.

36. Murphy KJ, Gailloud P, Venbrux A, Deramond H, Hanley D, Rigamonti D. Endovascular treatment of a grade IV transverse sinus dural arteriovenous fistula by sinus recanalization, angioplasty, and stent placement: technical case report. Neurosurgery. 2000; 46: 497-500; discussion -1.

37. Matsushima T, Suzuki SO, Fukui M, Rhoton AL, Jr., de Oliveira E, Ono M. Microsurgical anatomy of the tentorial sinuses. J Neurosurg. 1989; 71: 923-8.

38. Torok CM, Nogueira RG, Yoo AJ, Leslie-Mazwi TM, Hirsch JA, Stapleton CJ, et al. Transarterial venous sinus occlusion of dural arteriovenous fistulas using ONYX. Interv Neuroradiol. 2016; 22: 711-6.

39. Lv X, Zhang J, Li Y, Jiang C, Wu Z. Dural arteriovenous fistula involving the transverse sigmoid sinus presenting as chemosis. A case report. Neuroradiol J. 2008; 21: 428-32.

40. Kan P, Stevens EA, Warner J, Couldwell WT. Resolution of an anterior-inferior cerebellar artery feeding aneurysm with the treatment of a transverse-sigmoid dural arteriovenous fistula. Skull Base. 2007; 17: 205-10.

41. Kerolus MG, Chung J, Munich SA, Matsuda Y, Okada H, Lopes DK. An Onyx tunnel: reconstructive transvenous balloon-assisted Onyx embolization for dural arteriovenous fistula of the transverse-sigmoid sinus. J Neurosurg. 2017: $1-6$.

42. Eftekhar B, Morgan MK. Surgical management of dural arteriovenous fistulas of the transverse-sigmoid sinus in 42 patients. J Clin Neurosci. 2013; 20: 532-5.

43. Carlson AP, Alaraj A, Amin-Hanjani S, Charbel FT, Aletich V. Endovascular approach and technique for treatment of transverse-sigmoid dural arteriovenous fistula with cortical reflux: the importance of venous sinus sacrifice. J Neurointerv Surg. 2013; 5: 566-72

44. $\mathrm{Hu} Y \mathrm{~S}$, Lin $\mathrm{CJ}$, Wu HM, Guo WY, Luo CB, Wu CC, et al. Lateral Sinus Dural Arteriovenous Fistulas: Sinovenous Outflow Restriction Outweighs Cortical Venous Reflux as a Parameter Associated with Hemorrhage. Radiology. 2017; 285: 528-35.

45. Tellouck L, Schweitzer C, Barreau X, Colin J. [Dural arteriovenous fistula of the sigmoid sinus with a clinical expression on the opposite eye: A case report]. J Fr Ophtalmol. 2012; 35: 191 e1-6.

46. Li J, Ezura M, Takahashi A Yoshimoto T. Intracranial dural arteriovenous fistula with venous reflux to the brainstem and spinal cord mimicking brainstem infarction--case report. Neurol Med Chir (Tokyo). 2004; 44: 24-8.

47. Kamio Y, Hiramatsu H, Yamashita S, Kamiya M, Sugiura Y, Namba H. Dural Arteriovenous Fistula of the Transverse and Sigmoid Sinus Manifesting Ascending Dysesthesia: Case Report and Literature Review. NMC Case Rep J. 2015; 2: 4-8.

48. Naito I, Iwai $T$, Shimaguchi $H$, Suzuki $T$, Tomizawa $S$, Negishi $M$, et al. Percutaneous transvenous embolisation through the occluded sinus for transverse-sigmoid dural arteriovenous fistulas with sinus occlusion. Neuroradiology. 2001; 43: 672-6.

49. Lalwani AK, Dowd CF, Halbach VV. Grading venous restrictive disease in patients with dural arteriovenous fistulas of the transverse/sigmoid sinus. J Neurosurg. 1993; 79: 11-5.

50. Takemoto K, Higashi T, Sakamoto S, Inoue T. Successful sinus restoration for transverse-sigmoid sinus dural arteriovenous fistula complicated by multiple venous sinus occlusions: The usefulness of preoperative computed tomography venography. Surg Neurol Int. 2015; 6: 137.

51. Guo WY, Lee CJ, Lin CJ, Yang HC, Wu HM, Wu CC, et al. Quantifying the Cerebral Hemodynamics of Dural Arteriovenous Fistula in Transverse Sigmoid Sinus Complicated by Sinus Stenosis: A Retrospective Cohort Study. AJNR Am J Neuroradiol. 2017; 38: 132-8.

52. de Paula Lucas C, Prandini MN, Spelle L, Piotin M, Mounayer C, Moret J. Parallel transverse-sigmoid sinus harboring dural arteriovenous malformation. How to differentiate the pathological and normal sinus in order to treat and preserve patency and function. Acta Neurochir (Wien). 2010; 152: 523-7.

53. Caragine LP, Halbach VV, Dowd CF, Ng PP, Higashida RT. Parallel venous channel as the recipient pouch in transverse/sigmoid sinus dural fistulae. Neurosurgery. 2003; 53: 1261-6; discussion 6-7. 
54. Kiyosue H, Tanoue S, Okahara M, Hori Y, Kashiwagi J, Sagara Y, et al. Angioarchitecture of transverse-sigmoid sinus dural arteriovenous fistulas: evaluation of shunted pouches by multiplanar reformatted images of rotational angiography. AJNR Am J Neuroradiol. 2013; 34: 1612-20.

55. Katsaridis V, Papagiannaki C, Violaris C. Endovascular treatment of a bilateral ophthalmic-ethmoidal artery dural arteriovenous fistula. J Neuroophthalmol. 2007; 27: 281-4.

56. Borden JA, Wu JK, Shucart WA. A proposed classification for spinal and cranial dural arteriovenous fistulous malformations and implications for treatment. J Neurosurg. 1995; 82: 166-79.

57. Cognard C, Gobin YP, Pierot L, Bailly AL, Houdart E, Casasco A, et al. Cerebral dural arteriovenous fistulas: clinical and angiographic correlation with a revised classification of venous drainage. Radiology. 1995; 194: 671-80.

58. Rabinov JD, Yoo AJ, Ogilvy CS, Carter BS, Hirsch JA. ONYX versus n-BCA for embolization of cranial dural arteriovenous fistulas. J Neurointerv Surg. 2013; 5: 306-10.

59. Dawson RC, 3rd, Joseph GJ, Owens DS, Barrow DL. Transvenous embolization as the primary therapy for arteriovenous fistulas of the lateral and sigmoid sinuses. AJNR Am J Neuroradiol. 1998; 19: 571-6.

60. Abud TG, Houdart E, Saint-Maurice JP, Abud DG, Baccin CE, Nguyen AD, et al. Safety of Onyx Transarterial Embolization of Skull Base Dural Arteriovenous Fistulas from Meningeal Branches of the External Carotids also Fed by Meningeal Branches of Internal Carotid or Vertebral Arteries. Clin Neuroradiol. 2017.

61. Caplan JM, Kaminsky I, Gailloud P, Huang J. A single burr hole approach for direct transverse sinus cannulation for the treatment of a dural arteriovenous fistula. J Neurointerv Surg. 2015; 7: e5.

62. Liu JK, Choudhry OJ, Barnwell SL, Delashaw JB, Jr., Dogan A. Single stage transcranial exposure of large dural venous sinuses for surgically-assisted direct transvenous embolization of high-grade dural arteriovenous fistulas: technical note. Acta Neurochir (Wien). 2012; 154: 1855-9.

63. Layton KF. Embolization of an intracranial dural arteriovenous fistula using ultrasound-guided puncture of a pericranial venous pouch. Proc (Bayl Univ Med Cent). 2009; 22: 332-4.

64. Kasai K, Iwasa H, Yamada N, Asamoto S, Abe T, Nemoto S. Combined treatment of a dural arteriovenous malformation of the lateral sinus using transarterial and direct lateral sinus embolisation. Neuroradiology. 1996; 38: 494-6.

65. Piske RL, Campos CM, Chaves JB, Abicalaf R, Dabus G, Batista LL, et al. Dural sinus compartment in dural arteriovenous shunts: a new angioarchitectural feature allowing superselective transvenous dural sinus occlusion treatment. AJNR Am J Neuroradiol. 2005; 26: 1715-22.

66. Jittapiromsak P, Ikka L, Benachour N, Spelle L, Moret J. Transvenous balloon-assisted transarterial Onyx embolization of transverse-sigmoid dural arteriovenous malformation. Neuroradiology. 2013; 55: 345-50.

67. Deng JP, Zhang T, Li J, Yu J, Zhao ZW, Gao GD. Treatment of dural arteriovenous fistula by balloon-assisted transarterial embolization with Onyx. Clin Neurol Neurosurg. 2013; 115: 1992-7.

68. Zhao WY, Krings T, Yang PF, Liu JM, Xu Y, Li Q, et al. Balloon-assisted superselective microcatheterization for transarterial treatment of cranial dural arteriovenous fistulas: technique and results. Neurosurgery. 2012; 71: ons269-73; discussion ons73.

69. Kurata A, Suzuki S, Iwamoto K, Yamada M, Fujii K, Kan S. New Development of a Dural Arteriovenous Fistula (AVF) of the Superior Sagittal Sinus after Transvenous Embolization of a Left Sigmoid Sinus Dural AVF. Case Report and Review of the Literature. Interv Neuroradiol. 2006; 12: 363-8.

70. Nishijima M, Takaku A, Endo S, Kuwayama N, Koizumi F, Sato H, et al. Etiological evaluation of dural arteriovenous malformations of the lateral and sigmoid sinuses based on histopathological examinations. J Neurosurg. 1992; 76: 600-6.

71. Tominaga T, Shamoto H, Shimizu H, Watanabe M, Yoshimoto T. Selective loss of Purkinje cells in transverse and sigmoid dural arteriovenous fistulas. Report of two cases. J Neurosurg. 2003; 98: 617-20.

72. Nakagawa H, Kubo S, Nakajima Y, Izumoto S, Fujita T. Shifting of dural arteriovenous malformation from the cavernous sinus to the sigmoid sinus to the transverse sinus after transvenous embolization. A case of left spontaneous carotid-cavernous sinus fistula. Surg Neurol. 1992; 37: 30-8.

73. Kurl S, Vanninen R, Saari T, Hernesniemi J. Development of right transverse sinus dural arteriovenous malformation after embolisation of a similar lesion on the left. Neuroradiology. 1996; 38: 386-8.

74. Griessenauer CJ, He L, Salem M, Chua MH, Ogilvy CS, Thomas AJ. Middle meningeal artery: Gateway for effective transarterial Onyx embolization of dural arteriovenous fistulas. Clin Anat. 2016; 29: 718-28.

75. Kim ST, Jeong HW, Seo J. Onyx Embolization of Dural Arteriovenous Fistula, using Scepter C Balloon Catheter: a Case Report. Neurointervention. 2013; 8: $110-4$

76. Kim JW, Kim BM, Park KY, Kim DJ, Kim DI. Onyx Embolization for Isolated Type Dural Arteriovenous Fistula Using a Dual-Lumen Balloon Catheter. Neurosurgery. 2016; 78: 627-36.

77. Zhang G, Zhu S, Wu P, Xu S, Shi H. The transvenous pressure cooker technique: A treatment for brain arteriovenous malformations. Interv Neuroradiol. 2017; 23: 194-9.

78. Abud DG, de Castro-Afonso LH, Nakiri GS, Monsignore LM, Colli BO. Modified pressure cooker technique: An easier way to control onyx reflux. J Neuroradiol. 2016; 43: 218-22.
79. Puffer RC, Daniels DJ, Kallmes DF, Cloft HJ, Lanzino G. Curative Onyx embolization of tentorial dural arteriovenous fistulas. Neurosurg Focus. 2012; 32: E4.

80. Dabus G, Linfante I, Martinez-Galdamez M. Endovascular treatment of dural arteriovenous fistulas using dual lumen balloon microcatheter: technical aspects and results. Clin Neurol Neurosurg. 2014; 117: 22-7.

81. Gabrieli J, Clarencon F, Di Maria F, Chiras J, Sourour N. Occipital artery: a not so poor artery for the embolization of lateral sinus dural arteriovenous fistulas with Onyx. J Neurointerv Surg. 2017; 9: e8-e9.

82. Huo $\mathrm{X}, \mathrm{Li} \mathrm{Y}$, Jiang $\mathrm{C}, \mathrm{Wu} \mathrm{Z}$. Balloon-assisted endovascular treatment of intracranial dural arteriovenous fistulas. Turk Neurosurg. 2014; 24: 658-63.

83. Arat A, Cil BE, Vargel I, Turkbey B, Canyigit M, Peynircioglu B, et al. Embolization of high-flow craniofacial vascular malformations with onyx. AJNR Am J Neuroradiol. 2007; 28: 1409-14.

84. Shi ZS, Loh Y, Duckwiler GR, Jahan R, Vinuela F. Balloon-assisted transarterial embolization of intracranial dural arteriovenous fistulas. J Neurosurg. 2009; 110: 921-8.

85. Pop R, Manisor M, Wolff V, Aloraini Z, Tigan L, Kehrli P, et al. Balloon protection of the Labbe vein during transarterial embolization of a dural arterio-venous fistula. Interv Neuroradiol. 2015; 21: 728-32.

86. Tsuruta W, Matsumaru Y, Suzuki K, Takigawa T, Matsumura A. A useful side-hole on a guiding catheter for transvenous embolization of a transverse-sigmoid sinus dural arteriovenous fistula. Neurosurgery. 2008; 63: ONSE91-2; discussion ONSE2.

87. Shownkeen H, Yoo K, Leonetti J, Origitano TC. Endovascular treatment of transverse-sigmoid sinus dural arteriovenous malformations presenting as pulsatile tinnitus. Skull Base. 2001; 11: 13-23.

88. Wong GK, Poon WS, Yu SC, Zhu CX. Transvenous embolization for dural transverse sinus fistulas with occluded sigmoid sinus. Acta Neurochir (Wien). 2007; 149: 929-35; discussion 35-6.

89. Sugiu K, Tokunaga K, Nishida A, Sasahara W, Watanabe K, Ono S, et al. Triple-catheter technique in the transvenous coil embolization of an isolated sinus dural arteriovenous fistula. Neurosurgery. 2007; 61: 81-5; discussion 5.

90. Komiyama M, Ishiguro T, Matsusaka Y, Yasui T, Nishio A. Transfemoral, transvenous embolisation of dural arteriovenous fistula involving the isolated transverse-sigmoid sinus from the contralateral side. Acta Neurochir (Wien). 2002; 144: 1041-6; discussion 6.

91. Siekmann R, Weber W, Kis B, Kuhne D. Transvenous Treatment of a Dural Arteriovenous Fistula of the Transverse Sinus by Embolization with Platinum Coils and Onyx HD 500+. Interv Neuroradiol. 2005; 11: 281-6.

92. Jiang $\mathrm{C}, \mathrm{Lv} \mathrm{X}, \mathrm{Li} \mathrm{Y}, \mathrm{Wu} \mathrm{Z}$. Transarterial Onyx packing of the transverse-sigmoid sinus for dural arteriovenous fistulas. Eur J Radiol. 2011; 80: 767-70

93. de Castro-Afonso LH, Trivelato FP, Rezende MT, Ulhoa AC, Nakiri GS, Monsignore LM, et al. Transvenous embolization of dural carotid cavernous fistulas: the role of liquid embolic agents in association with coils on patient outcomes. J Neurointerv Surg. 2017.

94. Kessler I, Riva R, Ruggiero M, Manisor M, Al-Khawaldeh M, Mounayer C. Successful transvenous embolization of brain arteriovenous malformations using Onyx in five consecutive patients. Neurosurgery. 2011; 69: 184-93; discussion 93.

95. Limbucci N, Spinelli G, Nappini S, Renieri L, Consoli A, Rosi A, et al. Curative Transvenous Onyx Embolization of a Maxillary Arteriovenous Malformation in a Child: Report of a New Technique. J Craniofac Surg. 2016; 27: e217-9.

96. Lv X, Song C, He H, Jiang C, Li Y. Transvenous retrograde AVM embolization: Indications, techniques, complications and outcomes. Interv Neuroradiol. 2017; 23: 504-9.

97. Albuquerque FC, Ducruet AF, Crowley RW, Bristol RE, Ahmed A, McDougall CG. Transvenous to arterial Onyx embolization. J Neurointerv Surg. 2014; 6: 281-5

98. Johnson CS, Chiu A, Cheung A, Wenderoth J. Embolization of cranial dural arteriovenous fistulas in the liquid embolic era: A Sydney experience. J Clin Neurosci. 2017.

99. Levrier O, Metellus P, Fuentes S, Manera L, Dufour H, Donnet A, et al. Use of a self-expanding stent with balloon angioplasty in the treatment of dural arteriovenous fistulas involving the transverse and/or sigmoid sinus: functional and neuroimaging-based outcome in 10 patients. J Neurosurg. 2006; 104: 254-63.

100. Weber W, Kis B, Esser J, Berlit P, Kuhne D. Endovascular Treatment of a Dural Arteriovenous Fistula of the Transverse Sinus by Recanalisation, Angioplasty and Stent Deployment. A Case Report and Follow-up. Interv Neuroradiol. 2003; 9: 65-9.

101. Takada S, Isaka F, Nakakuki T, Mitsuno Y, Kaneko T. Torcular dural arteriovenous fistula treated via stent placement and angioplasty in the affected straight and transverse sinuses: case report. J Neurosurg. 2015; 122: 1208-13.

102. Yoshino K, Yasuhara T, Nakagawa M, Terai Y, Fujimoto S, Kusaka N. The rebuilding of normal venous circulation for transverse-sigmoid dural arteriovenous fistulas by percutaneous transluminal angioplasty. A case report. Interv Neuroradiol. 1999; 5 Suppl 1: 109-14.

103. Lv X, Jiang C, Li Y, Liu L, Liu J, Wu Z. Transverse-sigmoid sinus dural arteriovenous fistulae. World Neurosurg. 2010; 74: 297-305.

104. Lv X, Jiang C, Li Y, Yang X, Wu Z. Intraarterial and intravenous treatment of transverse/sigmoid sinus dural arteriovenous fistulas. Interv Neuroradiol. 2009; 15: 291-300. 
105. Dozic A, Cetkovic M, Marinkovic S, Mitrovic D, Grujicic M, Micovic M, et al. Vascularisation of the geniculate ganglion. Folia Morphol (Warsz). 2014; 73: 414-21.

106. Olteanu-Nerbe V, Uhl E, Steiger HJ, Yousry T, Reulen HJ. Dural arteriovenous fistulas including the transverse and sigmoid sinuses: results of treatment in 30 cases. Acta Neurochir (Wien). 1997; 139: 307-18.

107. Gross BA, Albuquerque FC, Moon K, McDougall CG. The road less traveled: transarterial embolization of dural arteriovenous fistulas via the ascending pharyngeal artery. J Neurointerv Surg. 2017; 9: 97-101.

108. Jiang Y, Li Y, Wu Z. Onyx distal embolization in transarterial embolization of dural arteriovenous fistula with subtotally isolated transverse-sigmoid sinus. A case report. Interv Neuroradiol. 2009; 15: 223-8.

109. Baltsavias G, Richter J, Hegemann S, Valavanis A. Complications of Sigmoid Sinus Transvenous Occlusion for the Endovascular Treatment of Dural Arteriovenous Shunts with Emphasis on Inner Ear Dysfunction. World Neurosurg. 2016; 88: 41-8.

110. Halbach VV, Higashida RT, Hieshima GB, Mehringer CM, Hardin CW. Transvenous embolization of dural fistulas involving the transverse and sigmoid sinuses. AJNR Am J Neuroradiol. 1989; 10: 385-92.

111. Yamauchi S, Nishio A, Ohata K. A case of isolated transverse sigmoid sinus dural arteriovenous fistula in which ipsilateral sensory neural hearing loss developed after transvenous embolization--letter to the editor. Neuroradiology. 2013; 55: 117-9.

112. Fermand M, Reizine D, Melki JP, Riche MC, Merland JJ. Long term follow-up of 43 pure dural arteriovenous fistulae (AVF) of the lateral sinus. Neuroradiology. 1987; 29: 348-53.

113. Noguchi K, Kuwayama N, Kubo M, Kamisaki Y, Tomizawa G, Kameda K, et al. Dural arteriovenous fistula involving the transverse sigmoid sinus after treatment: assessment with magnetic resonance digital subtraction angiography. Neuroradiology. 2007; 49: 639-43.

114. Ertl L, Bruckmann H, Kunz M, Patzig M, Brem C, Forbrig R, et al. Assessment and treatment planning of lateral intracranial dural arteriovenous fistulas in 3 $T$ MRI and DSA: A detailed analysis under consideration of time-resolved imaging of contrast kinetics (TRICKS) and ce-MRA sequences. Eur Radiol. 2016; 26 : 4284-92. 